\title{
Erratum to: Chronic neck pain and treatment of cognitive and behavioural factors: results of a randomised controlled clinical trial
}

\author{
Marco Monticone • Paola Baiardi • Carla Vanti • \\ Silvano Ferrari - Tiziana Nava $\cdot$ Catia Montironi · \\ Barbara Rocca $\cdot$ Calogero Foti $\cdot$ Marco Teli
}

Published online: 8 May 2012

(C) Springer-Verlag 2012

\section{Erratum to: Eur Spine J}

DOI 10.1007/s00586-012-2287-y

Following statement of the Acknowledgement was missing in the article.

This research was funded by AISD (Associazione Italiana per lo Studio del Dolore), 2007 annual grant entitled to Professor Leonardo Vecchiet.

The online version of the original article can be found under doi:10.1007/s00586-012-2287-y.

M. Monticone - C. Montironi · B. Rocca

Physical Medicine and Rehabilitation Unit, Scientific Institute of Lissone (Milan), Institute of Care and Research,

Salvatore Maugeri Foundation, IRCCS, Milan, Italy

P. Baiardi

Scientific Institute of Pavia, Institute of Care and Research,

Salvatore Maugeri Foundation, IRCCS, Pavia, Italy

P. Baiardi

Consorzio Valutazioni Biologiche e Farmacologiche,

Pavia University, Pavia, Italy

C. Vanti

School of Physiotherapy, Bologna University, Bologna, Italy

S. Ferrari

Manual Therapy Sciences, Padua University, Padua, Italy
T. Nava

School of Physiotherapy, University of Milan, Milan, Italy

C. Foti

Chair of Physical and Rehabilitation Medicine,

Tor Vergata University of Rome, Rome, Italy

M. Teli

Orthopaedic Spine Unit, Hospital of Legnano, Legnano, Italy

M. Teli ( $₫)$

Department of Orthopaedics, Ospedale Civile di Legnano,

Via Papa Giovanni Paolo II, 20025 Legnano, Italy

e-mail: marcoteli@hotmail.com;

marcogiuseppeangelo.teli@ao-legnano.it 